\title{
A Finer Look at the Causative-Inchoative Alternation
}

\author{
Christopher Piñón \\ Universität Düsseldorf
}

\section{Introduction}

The causative-inchoative alternation is a lexical alternation that characterizes pairs of verbs which stand in approximately the following semantic relation to each other: the intransitive member of the pair, a.k.a. an inchoative verb, denotes a change of state, and the transitive member of the pair, a.k.a. a causative-inchoative verb, denotes a bringing about of this change of state. The sentences in (1)-(3) illustrate the causative-inchoative alternation with typical pairs of alternating verbs.

(1) a. Rebecca broke the pencil.

b. The pencil broke.

(2) a. Maria opened the door.

b. The door opened.

a. Thomas dried the clothes.

b. The clothes dried.

For example, the sentence in (1b), which contains the inchoative verb break incho $_{\text {, }}$ describes a change of state in which the pencil becomes broken, whereas the sentence in (1a), which contains its causative-inchoative counterpart break caus-incho, , describes Rebecca's bringing it about that the pencil becomes broken.

There are two central questions looming in the background of the causativeinchoative alternation: the first is why not every inchoative verb has a causativeinchoative counterpart, and the second - which is really the inverse of the first-is why not every causative-inchoative verb has an inchoative counterpart. For examples bearing on the first question, consider the contrasts in (4)-(6). ${ }^{1}$

a. The roses bloomed.

b. *Rebecca bloomed the roses.

a. The iron gate rusted away.

b. *Maria rusted away the iron gate.

a. The fire burned out.

b. *The campers burned out the fire.

Since these and other such inchoative verbs can appear unproblematically in periphrastic causative constructions (e.g., Rebecca caused the roses to bloom or Rebecca made the roses bloom), we must conclude that the changes of state which they denote can very well be caused. Two other inchoative verbs that lack a causativeinchoative partner are decay (The dead body decayed ${ }^{*}$ We decayed the dead body) and grow up. ${ }^{2}$ 
For cases in which a causative-inchoative verb lacks an inchoative counterpart, consider the following contrasts: ${ }^{3}$

(7) a. Rebecca broke her promise.

b. *Her promise broke.

(8) a. Maria cracked the secret code.

b. *The secret code cracked.

(9) a. The baby dirtied his diapers.

b. *His diapers dirtied.

For example, although it is evident that if the baby dirtied his diapers, then his diapers became dirty (in the relevant sense), the inchoative verb * dirty incho $_{\text {is nev- }}$ ertheless unacceptable, as seen in (9b). Similar contrasts have been discussed by Brousseau and Ritter (1991, sect. 3), Levin and Rappaport Hovav (1995, pp. 85-86, 104-105), and van Voorst (1995, sect. 6.2). Two other causative-inchoative verbs that lack an inchoative counterpart are cough up (e.g., The baby coughed.up his food $/{ }^{*}$ His food coughed up) and humidify.

The existence of these two types of examples implies the perhaps surprising conclusion that any general account of the causative-inchoative alternation in which causative-inchoative verbs are derived from inchoative verbs or vice versa is misguided. For suppose that the preferred account claims that causative-inchoative verbs are derived from inchoative verbs. Then there will be no straightforward way to derive causative-inchoative verbs like those in (7)-(9). Alternatively, suppose that the preferred account states that inchoative verbs are derived from causativeinchoative verbs. Then there will be no straightforward way to derive inchoative verbs like those in (4)-(6). Note that this apparent paradox could be resolved if causative-inchoative verbs and inchoative verbs were both derived (under differing conditions) from a third source, for then the derivation of a causative-inchoative verb or an inchoative verb from the third source might not always be well-defined. To explore this possibility further, let's consider how the causative-inchoative alternation is expressed crosslinguistically.

Haspelmath (1993) presents the results of a survey of 31 alternating pairs of verbs in 21 languages. Basing his classification on the surface morphology of the verbs in question, he finds that by far the predominant pattern is for inchoative verbs to be derived from causative-inchoative verbs (or what he calls anticausative alternations). Polish, for example, regularly employs the reflexive clitic sie to derive inchoative verbs from causative-inchoative verbs:

a. Rebecca złamała ołówek. (złamać 'break caus ')

Rebecca broke pencil

'Rebecca broke the pencil.'

b. Ołówek złamał się. (złamać się 'break caus-incho ') pencil broke refl

'The pencil broke.' 
(11) a. Maria otworzyła drzwi. (otworzyć 'open caus-incho $_{\text {') }}$

Maria opened door

'Maria opened the door.'

b. Drzwi otworzyły się. (otworzyć się 'open incho $_{\text {') }}$

door opened refl

'The door opened.'

(12) a. Thomas wysuszył ubranie. (wysuszyć 'dry caus-incho ')

Thomas dried clothes

'Thomas dried the clothes.'

b. Ubranie wysuszyło się. (wysuszyć się 'dry incho $_{\text {') }}$

clothes dried refl

'The clothes dried.'

Two other languages that favor anticausative alternations (though not quite as dramatically as Polish) are French and Hebrew.

The second most frequent pattern in Haspelmath's survey is for causativeinchoative verbs to be derived from inchoative verbs (or what Haspelmath calls causative alternations). Khalka Mongolian, for instance, strongly favors causative alternations: ${ }^{4}$
a. ser-ex 'wake up incho $\rightarrow$ ser-e-ex 'wake up caus-incho'
b. ongoj-x 'open incho $\rightarrow$ ongoj-lg-ox 'open caus-incho
c. xat-ax 'dry incho ' $\rightarrow$ xat-a-ax 'dry caus-incho'

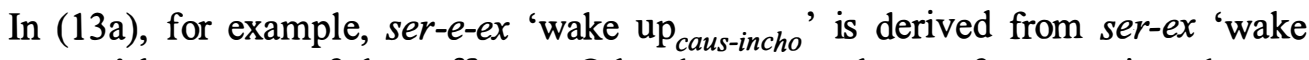
up $_{\text {incho }}$ ' by means of the suffix $-e$. Other languages that prefer causative alternations include Hindi/Urdu and Turkish.

The third most common pattern that Haspelmath establishes is for both causative-inchoative verbs and inchoative verbs to be derived from a common stem (or what he calls equipollent alternations). Hungarian is a language that favors equipollent alternations: ${ }^{5}$

(14) a. Rebecca felébresztette a gyereket. (felébreszt 'wake up caus-incho') ') Rebecca woke.up the child

b. A gyerek felébredt. (felébred 'wake up incho $_{\text {') }}$ the child woke.up

a. Maria kinyitotta az ajtót. (kinyit 'open caus-incho ') Maria opened the door

b. Az ajtó kinyílt. (kinyílik 'open incho ') the door opened

a. Thomas megszárította a ruhát. (megszárít 'dry caus-incho ') Thomas dried the clothes

b. A ruha megszáradt. (megszárad 'dry ${ }_{\text {incho }}$ ') the clothes dried 


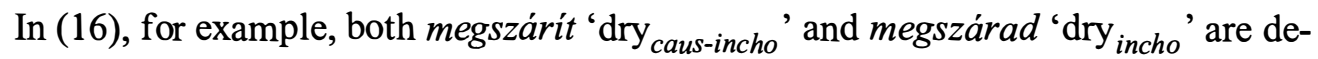
rived from the common stem megszár- (or szár-, given that meg- is a perfective preverb) by means of -it and - $a d$, respectively. Other languages that favor equipollent alternations include Georgian and Japanese.

The fourth and fifth most predominant patterns in Haspelmath's survey are characterized by what he calls labile alternations and suppletive alternations, respectively. In labile alternations, causative-inchoative verbs and inchoative verbs have the same form, e.g., break caus-incho $/ b_{r e a k_{\text {incho }}}$. English is unusual in favoring labile alternations, but languages such as German and Greek also have a fair number of them. Finally, most languages have a few suppletive alternations as well, i.e., alternating pairs of verbs that are not morphologically related, e.g., kill/die.

In the face of this apparent morphological anarchy, ${ }^{6}$ it would be easy to despair and to conclude that languages just pick and choose and that no general analysis of the causative-inchoative alternation that respects the morphological facts is possible. Now, although it is undeniable that languages really do pick and choose, it does not necessarily follow that no general analysis of the causative-inchoative alternation that respects the morphology is possible. On the contrary, it seems to me that the analytic strategy to pursue in this case has to be that of looking for the least common denominator. More precisely, we should try to develop an analysis that in no instance outright contradicts the surface morphology but at the same time does not always naively take the surface morphology at face value.

To see what I have in mind, recall the Polish examples in (10)-(12), where the reflexive clitic sie seems to derive inchoative verbs from causative-inchoative verbs. I say 'seems to' because on a naive (i.e., surface-oriented) interpretation of the data this is what it does. However, it would be consistent with the facts to attribute a slightly different role to sie, namely, one in which it derives an inchoative verb from an alternating verb stem. On this view, Polish would actually have equipollent alternations and not anticausative alternations after all, contrary to what the surface morphology at first suggests. Polish would differ from Hungarian (see (14)-(16)) not in not having equipollent alternations but rather in not overtly marking the derivation of a causative-inchoative verb from an alternating verb stem. If we take (12) as an example, this view would postulate a verb stem wysuszyćstem 'dry stem $^{\text {' from which both the causative-inchoative verb wysuszyc' 'dry }}$ caus-incho' and the inchoative verb wysuszyć sie 'dry ${ }_{\text {incho' }}$ ' would be derived. ${ }^{7}$ However, only the derivation of the inchoative verb would be overtly marked in Polish. In contrast, although Khalka Mongolian (see (13)) is a language that favors causative alternations on the surface, from the present perspective this would mean that it typically only marks the derivation of a causative-inchoative verb from its alternating verb stem. In sum, as outlandish as it may at first sound, equipollent alternations provide the least common denominator that we are looking for.

I depict this new perspective on the causative-inchoative alternation as in Figure 1, where the dashed arrows indicate the direction of derivation. Notice that since no attempt is made to directly derive causative-inchoative verbs from inchoative verbs or vice versa, no air of paradox arises when either the inchoative verbs are missing (as in (7)-(9)) or the causative-inchoative verbs are missing (as in (4)-(6)). 


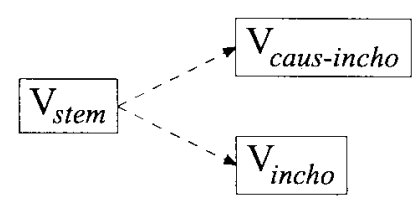

Figure 1: A new model of the causative-inchoative alternation

Of course, a story still has to be told that tries to account for why such verbs are missing, but the point here is that the conceptual difficulty that would arise from attempting to derive existing verbs from nonexisting verbs does not arise on this view. Furthermore, this model succeeds in accommodating the variety of morphological reflexes of the causative-inchoative alternation without outright contradicting any of them. In the next section I will present the semantic analysis that underlies the new model, and in section 3 I will briefly compare it to three previous analyses of the causative-inchoative alternation.

\section{The Finer Look}

The strategy will be to specify semantic representations for alternating verb stems, causative-inchoative verbs, and inchoative verbs, showing how the latter two can be derived from the first in a systematic way. My account of the contrasts in (4)(6) and (7)-(9) will rely on a couple of constraints that govern the derivation of causative-inchoative verbs and inchoative verbs. Essentially, the contraint governing the derivation of causative-inchoative verbs states that the types of events denoted by causative-inchoative verbs should possibly have an agent, whereas the constraint on the derivation of inchoative verbs states that the types of events denoted by inchoative verbs should not necessarily be caused by an agent. As I will show, the effect of these two constraints is to exclude causative-inchoative verbs when the changes of state in question either involve an agent or are not caused by an agent (as in (4)-(6)) and to rule out inchoative verbs when the changes of state in question are always caused by an agent (as in (7)-(9)). However, before coming to these consequences of the analysis, let's first set the stage for the analysis itself.

\subsection{Preliminaries}

I will formulate the analysis in a many-sorted intensional type-theoretic language $L$ with identity. I assume a standard possible worlds semantics for $L$ in which the accessibility relation $R$ is reflexive, symmetric, and transitive (i.e., an equivalence relation), hence any world is accessible from any other. ${ }^{8}$ Accordingly, I am interested in the interpretation of $\diamond$ and $\square$ as metaphysical possibility and metaphysical necessity, respectively. Although I will not formally specify the models for $L$ (because they are standard), in what follows I will introduce those special features (sorted variables and distinguished predicates) of $L$ that play a role in the analysis to be presented in the next section. 
$L$ presupposes three pairwise disjoint sorts (or domains) of objects and has a set of sorted individual variables for each of them: a domain of ordinary objects ( $x$, $\mathrm{y}, \ldots)$, one of events $\left(\mathrm{e}, \mathrm{e}^{\prime}, \ldots\right)$, and one of states $\left(\mathrm{s}, \mathrm{s}^{\prime}, \ldots\right)$. Note that the domain of events includes both events proper and processes. The union of the domain of events and that of states constitutes the domain of eventualities $\left(\mathrm{v}, \mathrm{v}^{\prime}, \ldots\right)$.

In addition, $L$ has a group of distinguished predicates known as thematic relations that characterize the participants of eventualities. The kinds of participants that are relevant here are agents (Agent), instruments (Instrument), natural forces (Natural-Force) and themes (Theme). Technically, thematic relations are two-place relations between eventualities and ordinary objects. I assume that at most one object can stand in a particular thematic relation to a given eventuality, hence any eventuality can have at most one agent, etc. I also postulate that whereas agents, instruments, and natural forces may only participate in events, themes may participate in either events or states. I understand 'instrument' in the traditional sense of a tool or object manipulated by an agent (e.g., the key in Maria opened the door with the key or The key opened the door) and 'natural force' as a physical force that is neither an instrument nor an agent (e.g., the wind in The wind opened the door or the rain in The rain pounded against the window). I further postulate that agents, instruments, and natural forces are mutually exclusive in that no participant of an event can be both an agent and an instrument, an agent and a natural force, or an instrument and a natural force. For example, although the usual way for Maria to open the door is for her to do so as an agent, another way is for her to accidently trip and fall against the door (having lost all control), thereby opening it, and in this case she would act as a natural force (and not as an agent). However, I do not take this kind of mutual exclusiveness to be characteristic of thematic relations in general. In particular, I consider it possible for an object to be both the agent and the theme of an event (e.g., Rebecca in Rebecca jumped into the water). Since many verbs (e.g., open) allow for their subject to be realized as an agent, an instrument, or a natural force, it is useful to define performers to be agents, instruments, or natural forces: ${ }^{9}$

$$
\operatorname{Performer}(e, x) \stackrel{\text { def }}{=} \operatorname{Agent}(e, x) \vee \text { Instrument }(e, x) \vee \text { Natural-Force }(e, x)
$$

I emphasize that 'agent' should be understood in a sufficiently broad sense, as covering organisms that engage in 'goal-directed' behavior, whether or not they do so intentionally or consciously. In this sense, not only people but also animals and plants can be agents. However, natural forces such as the wind or the rain would still not be agents, because they do not exhibit goal-directed behavior (or at least we do not usually attribute goal-directed behavior to them, given that they are not living systems). ${ }^{10}$ I do not wish to imply that one should never distinguish a narrower sense of 'agent' but only that the broader sense seems more apt for the analysis of the causative-inchoative alternation.

The next distinguished notion is complete temporal precedence $(\prec)$, a twoplace relation between eventualities that is irreflexive, asymmetric, and transitive (i.e., a strict partial order). With the help of complete temporal precedence, we can define immediate temporal precedence $(\ll)$ as follows: 


$$
\begin{gathered}
\mathrm{v} \ll \mathrm{v}^{\prime} \stackrel{\text { def }}{=} \mathrm{v} \prec \mathrm{v}^{\prime} \wedge \neg \exists \mathrm{v}^{\prime \prime}\left[\mathrm{v} \prec \mathrm{v}^{\prime \prime} \wedge \mathrm{v}^{\prime \prime} \prec \mathrm{v}^{\prime}\right] \\
\text { (immediate temporal precedence) }
\end{gathered}
$$

Basically, if one eventuality immediately temporally precedes another, then no third eventuality can temporally come between them.

Another notion is proper part $(\sqsubset)$, a two-place relation between ordinary objects or eventualities that is also a strict partial order. In addition, proper part satisfies the condition that no object or eventuality has only a single proper part. We can employ complete temporal precedence and proper part to define final proper $\operatorname{part}\left(\sqsubset_{\text {fin }}\right)$ as follows:

$$
\mathrm{v} \sqsubset_{\text {fin }} \mathrm{v}^{\prime} \stackrel{\text { def }}{=} \mathrm{v} \sqsubset \mathrm{v}^{\prime} \wedge \neg \exists \mathrm{v}^{\prime \prime}\left[\mathrm{v}^{\prime \prime} \sqsubset \mathrm{v}^{\prime} \wedge \mathrm{v} \prec \mathrm{v}^{\prime \prime}\right]
$$

(final proper part)

Essentially, one eventuality is a final proper part of another only if it is a proper part of the latter and it ends with but begins later than the latter.

The notion of a change of state is a four-place relation between events, ordinary objects, states, and types of states, as defined in (20). The idea is that an object $x$ comes to be in a state $s$ of type $P$ by virtue of $e$ just in case $x$ is the theme of $e, e$ immediately precedes $s, s$ is of type $P, x$ is the theme of $s$, and no proper part $e^{\prime}$ of $e$ that is not also a final proper part of $e$ is immediately followed by a state $s^{\prime}$ of type $P$ of which $x$ is the theme. Note that $P$ in $(20)$ is a one-place predicate variable of states.

$$
\begin{aligned}
& \text { Change-of-State }(e, x, s, P) \stackrel{\text { def }}{=} \text { Theme }(e, x) \wedge e \ll s \wedge P(s) \wedge \\
& \quad \text { Theme }(s, x) \wedge \\
& \quad \forall e^{\prime}\left[e^{\prime} \sqsubset e \wedge \neg\left(e^{\prime} \sqsubset \text { fin } e\right) \rightarrow \neg \exists s^{\prime}\left[e^{\prime} \ll s^{\prime} \wedge P\left(s^{\prime}\right) \wedge \text { Theme }\left(s^{\prime}, x\right)\right]\right] \\
& \text { (change of state) }
\end{aligned}
$$

For example, if the pencil breaks, then it undergoes a change that results in a state in which it is broken.

A pure change of state is a change of state in which the theme is not also an agent:

$$
\begin{aligned}
& \text { Pure-Change-of-State }(e, y, s, P) \stackrel{\text { def }}{=} \text { Change-of-State }(e, y, s, P) \wedge \\
& \neg \text { Agent }(e, y) \\
& \quad \text { (pure change of state) }
\end{aligned}
$$

A change of state in which the pencil breaks is a pure change of state because the pencil is not an agent, but a change of state in which Rebecca jumps into the water is not a pure change of state because Rebecca also acts as an agent in this case.

The final distinguished notion that $L$ presupposes is cause (Cause), a twoplace relation between events. Cause is also postulated to be a strict partial order, and I add the condition that if an event $e$ causes an event $e^{\prime}$, then no part $e^{\prime \prime}$ of $e^{\prime}$ completely temporally precedes $e$ (where 'part' here means either proper part or identity). Notice that this condition permits $e$ and $e^{\prime}$ to temporally overlap. Cause may be thought of as a restriction to events of a more general causal relation that 
applies to eventualities (including states). There are no doubt other conditions that one could impose on cause, ${ }^{11}$ and I also do not mean to imply that this is only causal notion worth considering. Indeed, there may well be a (related) causal relation that applies to propositions (or facts) as opposed to eventualities. But be that as it may, my immediate concern is to define a notion of agent-cause in terms of cause and agent as follows:

$$
\begin{aligned}
& \text { Agent-Cause }\left(e, x, e^{\prime}\right) \stackrel{\text { def }}{=} \operatorname{Agent}(e, x) \wedge \text { Cause }\left(e, e^{\prime}\right) \wedge \\
& \forall e^{\prime \prime}\left[\text { Cause }\left(e, e^{\prime \prime}\right) \wedge\left(\text { Cause }\left(e^{\prime \prime}, e^{\prime}\right) \vee e^{\prime \prime}=e^{\prime}\right) \rightarrow \neg \exists y\left[\text { Agent }\left(e^{\prime \prime}, y\right)\right]\right] \\
& \quad(\text { agent-cause })
\end{aligned}
$$

In prose, an ordinary object $x$ in an event $e$ agent-causes an event $e^{\prime}$ just in case $x$ is the agent of $e, e$ causes $e^{\prime}$, and any intermediate event $e^{\prime \prime}$ in the causal chain between $e$ and $e^{\prime}$ (including, as a limiting case, $e^{\prime}$ itself) lacks an agent. In other words, agent-cause constrains a causal chain to begin with an agent and to lack an agent anywhere else along the causal chain.

The motivation behind agent-cause is that if Rebecca breaks the pencil, then she does so 'directly' in the sense that she does not do so by making someone else break it for her. Of course, she may use any variety of instruments to break the pencil, including a pair of pliers, a hammer, or her hands, but none of these would be agents. If Rebecca makes someone else break the pencil for her, then she causes the pencil to break but she does not agent-cause it to break. And in this case it would also seem false to assert that Rebecca broke the pencil.

A straightforward consequence of the definitions of change of state, pure change of state, and agent-cause is that if an ordinary object $x$ in an event $e$ agentcauses an event $e^{\prime}$ that is a change of state of type $P$, then $e^{\prime}$ is a pure change of state:

$$
\begin{aligned}
& \text { Fact. } \quad \forall \mathrm{e} \forall \mathbf{x} \forall \mathrm{e}^{\prime} \forall \mathrm{y} \forall \mathbf{s} \forall \mathrm{P}\left[\text { Agent-Cause }\left(\mathrm{e}, \mathrm{x}, \mathrm{e}^{\prime}\right) \wedge\right. \\
& \text { Change-of-State }\left(\mathrm{e}^{\prime}, \mathrm{y}, \mathrm{s}, \mathrm{P}\right) \rightarrow \\
& \text { Pure-Change-of-State } \left.\left(\mathrm{e}^{\prime}, \mathrm{y}, \mathrm{s}, \mathrm{P}\right)\right]
\end{aligned}
$$

In sum, $L$ has the distinguished predicates Agent, Instrument, Natural-Force, Theme, $\prec, \sqsubset$, and Cause, in addition to its three types of sorted individual variables. Together with the modal operators, these (or rather the notions that they stand for) are what figure in the general analysis of the causative-inchoative alternation, as we will now see.

\subsection{The Causative-Inchoative Alternation}

As discussed in section 1, the leading idea of the analysis is that a causativeinchoative verb and its inchoative counterpart are both derived from an alternating verb stem. The verb stem is their common source, both morphologically (disregarding suppletive alternations such as kill/die) and semantically.

In order to provide an appropriate representation for alternating stems, I first define two relations that figure centrally in it. As seen in Figure 2, an inchoative 


$$
\text { Inchoative }(e, x, P) \stackrel{\text { def }}{=} \exists s[\text { Change-of-State }(e, x, s, P)]
$$

Figure 2: Inchoative component

$$
\begin{aligned}
& \text { Causative }\left(e, x, e^{\prime}\right) \stackrel{\text { def }}{=} \text { Performer }(e, x) \wedge \text { Cause }\left(e, e^{\prime}\right) \wedge \\
& \quad\left(\text { Agent }(e, x) \rightarrow \text { Agent-Cause }\left(e, x, e^{\prime}\right)\right)
\end{aligned}
$$

Figure 3: Causative component

component is a three-place relation between events $e$, ordinary objects $x$, and state types $P$ such that $x$ undergoes a change in $e$ so as to be in a state $s$ of type $P .{ }^{12}$ And as shown in Figure 3, a causative component is a three-place relation between events $e$, ordinary objects $x$, and events $e^{\prime}$ such that $x$ is the performer of $e, e$ causes $e^{\prime}$, and if $x$ is the agent of $e$, then $x$ in $e$ agent-causes $e^{\prime}$.

We can then define the notion of a causative-inchoative alternating pair as in Figure 4. Subject to a choice of state type $P$ and relations $R$ and $R^{\prime}$, a causativeinchoative alternating pair is an ordered pair of relations: its first member is a twoplace relation between events $e$ and ordinary objects $x$ such that $e$ and $x$ stand in relation $R(P)$ and it is required that $R(P)$ imply the inchoative component Inchoative $(P)$; and its second member is a three-place relation between events $e$, ordinary objects $x$, and events $e^{\prime}$ such that $e, x, e^{\prime}$ stand in relation $R^{\prime}$ to each other and it is required that $R^{\prime}$ imply the causative component Causative. The idea is that although we do not wish to fix the precise values of the relations $R(P)$ and $R^{\prime}$ in advance, we can constrain the range of their values by requiring them to imply the inchoative component Inchoative $(P)$ and the causative component Causative, respectively. This allows for the possibility that $R(P)$ and $R^{\prime}$ are actually more specific relations than Inchoative $(P)$ or Causative. In essence, then, a causative-inchoative alternating pair is an ordered pair of relations the first member of which is a type of inchoative component and the second member of which is a type of causative component.

Alternating verb stems can be represented as causative-inchoative alternating pairs, subject to a choice of $P, R$, and $R^{\prime}$. For example, the verb stem break $k_{\text {stem }}$ can be compactly represented as in (24), where Be-Broken is a one-place predicate of states:

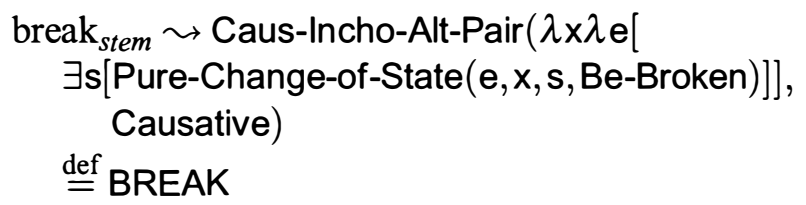

Recall from (21) that since pure changes of state are changes of state, they entail an inchoative component.

Naturally, not every choice of $P, R$, and $R^{\prime}$ will yield a causative-inchoative alternating pair that represents an actual alternating verb stem, even if we fix $R(P)$ and $R^{\prime}$ to be Inchoative $(P)$ and Causative, respectively. For instance, English appears to lack an alternating verb stem that is based on the state type Be-Happy, i.e., 


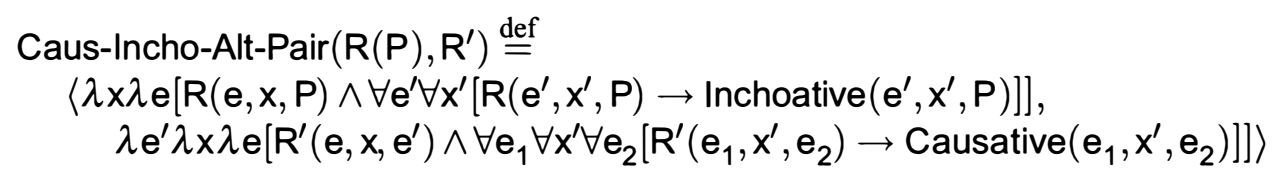

Figure 4: Causative-inchoative alternating pair

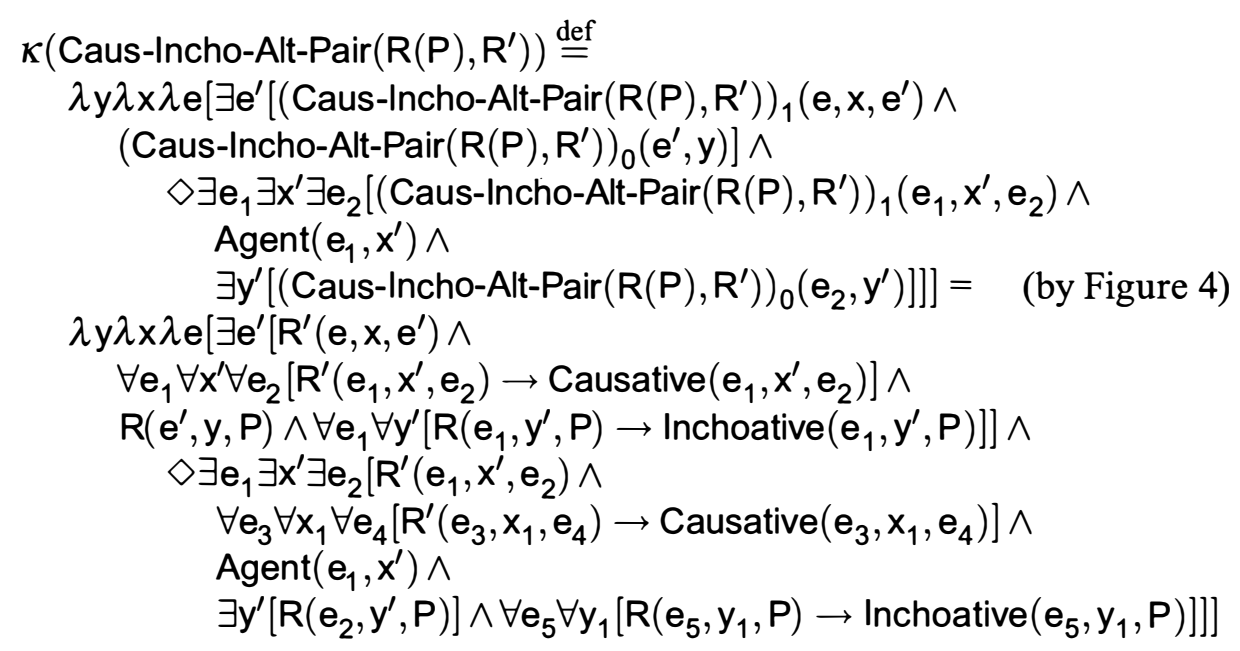

Figure 5: Causative-inchoative derivative

there is no alternating verb pair corresponding to make happy/become happy. Accordingly, it is probably best to think of English or any natural language as having a largely lexicalized inventory of alternating verb stems that can be represented as causative-inchoative alternating pairs, for different and largely fixed choices of $P$, $R$, and $R^{\prime}$.

The notion of a causative-inchoative derivative is defined as in Figure 5, where $(\cdot)_{0}$ and $(\cdot)_{1}$ denote functions (a.k.a. inverse functions) that pick out the first member and the second member, respectively, of an ordered pair of elements. ${ }^{13}$ As seen in Figure 5, subject to a choice of $P, R$, and $R^{\prime}$, the effect of applying the function $\kappa$ (kappa) to a causative-inchoative alternating pair is to select and strategically merge the two members of the alternating pair, adding the requirement that it be possible for there to be events of this type (causings of a change of state) that have an agent. More specifically, the result (a causative-inchoative derivative) is a three-place relation between events $e$, ordinary objects $x$, and ordinary objects $y$ such that (i) $e$ and $x$ stand in relation $R^{\prime}$ to an event $e^{\prime}$ with the requirement that $R^{\prime}$ imply the causative component Causative, (ii) $e^{\prime}$ and $y$ stand in relation $R(P)$ with the requirement that $R(P)$ imply the inchoative component Inchoative $(P)$, and (iii) it is possible for there to be a causing of a change of state of this type in which the performer is an agent.

Subject to a choice of $P, R$, and $R^{\prime}$, the derivation of a causative-inchoative verb from its alternating verb stem can be represented by the application of $\kappa$ to an causative-inchoative alternating pair. In (25) I introduce an operator $(\cdot)_{\kappa}$ that applies to alternating verb stems, yielding causative-inchoative verbs, and which is 


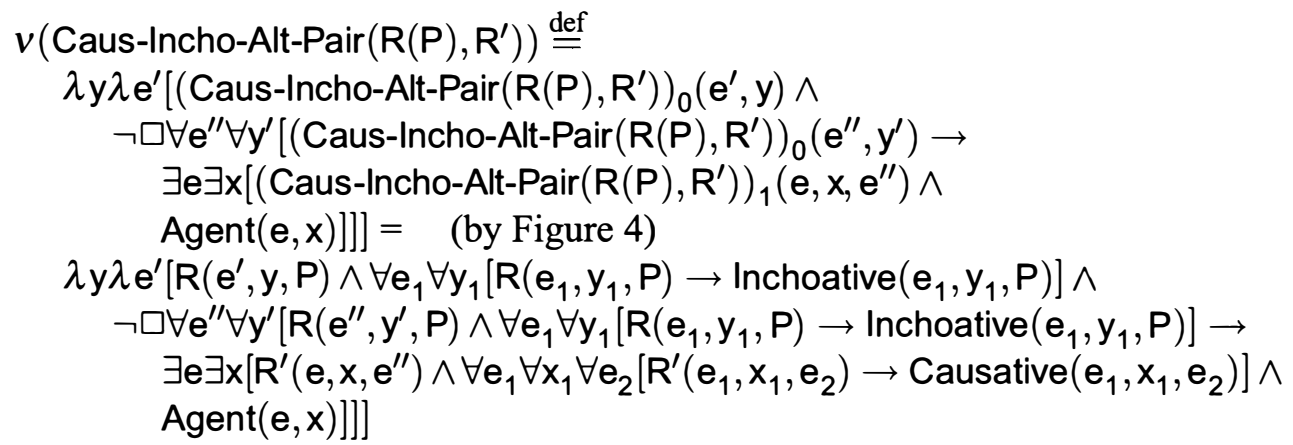

Figure 6: Inchoative derivative

represented as the function $\kappa$ of $L$, and in (26) I provide the analysis of the causativeinchoative verb break $_{\text {caus-incho }}$ as a causative-inchoative derivative. ${ }^{14}$

$$
\begin{aligned}
& \left(\mathrm{V}_{\text {stem }}\right)_{\kappa}\left(=\mathrm{V}_{\text {caus-incho }}\right) \sim \kappa\left(\text { Caus-Incho-Alt-Pair }\left(\mathrm{R}(\mathrm{P}), \mathrm{R}^{\prime}\right)\right) \\
& \text { (where } \mathrm{V}_{\text {stem }} \text { is an alternating verb stem) } \\
& \left(\text { break }_{\text {stem }}\right)_{\kappa}\left(=\text { break }_{\text {caus-incho }}\right) \leadsto \kappa(\text { BREAK })=\quad(\text { by (24) and Figure 5) } \\
& \lambda y \lambda \times \lambda e\left[\exists e ^ { \prime } \left[\text { Causative }\left(e, x, e^{\prime}\right) \wedge\right.\right. \\
& \left.\left.\exists \text { s[Pure-Change-of-State }\left(\mathrm{e}^{\prime}, \mathrm{y}, \mathrm{s}, \mathrm{Be}-\text { Broken }\right)\right]\right] \wedge \\
& \diamond \exists e_{1} \exists x^{\prime} \exists e_{2}\left[\text { Causative }\left(e_{1}, x^{\prime}, e_{2}\right)\right) \wedge \operatorname{Agent}\left(e_{1}, x^{\prime}\right) \wedge \\
& \left.\left.\exists y^{\prime} \exists s^{\prime}\left[\text { Pure-Change-of-State }\left(e_{2}, y^{\prime}, s^{\prime}, \text { Be-Broken }\right)\right]\right]\right]
\end{aligned}
$$

In English, of course, the derivation of a causative-inchoative verb from its alternating verb stem lacks a morphological reflex, but this is not generally the case in languages that favor causative alternations or equipollent alternations (in Haspelmath's terms). Recall from (13a) that in Khalka Mongolian the causative-inchoative verb ser-e-ex 'wake up caus-incho' differs from its inchoative counterpart ser-ex 'wake up $_{\text {incho }}$ ' by virtue of the affix $-e$. In the present analysis, $-e$ is a reflex of the deriva-

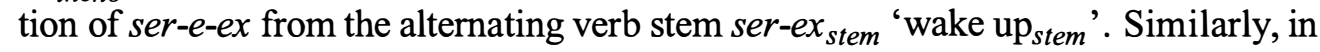
the Hungarian example in (16a) the suffix -it is a reflex of the derivation of megszárit

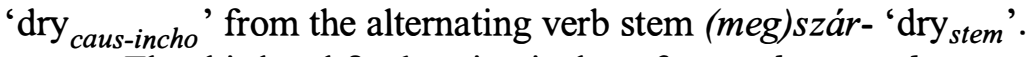

The third and final notion is that of an inchoative derivative, represented by a function $v(\mathrm{nu})$ that also applies to a causative-inchoative alternating pair, relative to a choice of $P, R$, and $R^{\prime}$, as defined in Figure 6. An inchoative derivative is a twoplace relation between events $e^{\prime}$ and ordinary objects $y$ such that (i) $e^{\prime}$ and $y$ stand in relation $R(P)$ with the requirement that $R(P)$ imply the inchoative component Inchoative $(P)$, and (ii) it is not necessary for all changes of state of this type to be caused by a performer that is an agent.

It should now come as no surprise that the derivation of an inchoative verb from its alternating verb stem can be treated as the application of $v$ to an causativeinchoative alternating pair, subject to a choice of $P, R$, and $R^{\prime}$. Parallel to (25) and (26), in (27) I introduce an operator $(\cdot)_{v}$ that applies to alternating verb stems, yielding inchoative verbs, and which is represented as the function $v$ of $L$, and in (28) I give the analysis of the inchoative verb break $_{\text {incho }}$ as an inchoative derivative. 


$$
\begin{aligned}
& \left(\mathrm{V}_{\text {stem }}\right)_{v}\left(=\mathrm{V}_{\text {incho }}\right) \sim v\left(\text { Caus-Incho-Alt-Pair }\left(\mathrm{R}(\mathrm{P}), \mathrm{R}^{\prime}\right)\right) \\
& \left(\text { where } \mathrm{V}_{\text {stem }} \text { is an alternating verb stem }\right) \\
& \left(\text { break }_{\text {stem }}\right)_{v}\left(=\text { break }_{\text {incho }}\right) \sim v(\mathrm{BREAK})=\quad(\text { by }(24) \text { and Figure } 6) \\
& \lambda \mathrm{y} \lambda \mathrm{e}^{\prime}\left[\exists \mathrm{s}\left[\text { Pure-Change-of-State }\left(\mathrm{e}^{\prime}, \mathrm{y}, \mathrm{s}, \text { Be-Broken }\right)\right] \wedge\right. \\
& \neg \square \forall \mathrm{e}^{\prime \prime} \forall \mathrm{y}^{\prime}\left[\exists \mathrm{s}^{\prime}\left[\text { Pure-Change-of-State }\left(\mathrm{e}^{\prime \prime}, \mathrm{y}^{\prime}, \mathrm{s}^{\prime}, \text { Be-Broken }\right)\right] \rightarrow\right. \\
& \left.\left.\exists \mathrm{e} \exists \mathrm{x}\left[\text { Causative }\left(\mathrm{e}, \mathrm{x}, \mathrm{e}^{\prime \prime}\right) \wedge \text { Agent }(\mathrm{e}, \mathrm{x})\right]\right]\right]
\end{aligned}
$$

Languages that favor anticausative alternations or equipollent alternations (again, in Haspelmath's terms) regularly mark the derivation of an inchoative verb from its alternating verb stem. Indeed, recall that according to Haspelmath's survey anticausative alternations constitute the predominant pattern of the causative-inchoative alternation crosslinguistically. For example, in the present approach one function of the reflexive clitic sie in Polish is to mark the derivation of inchoative verbs from alternating stems: in (10b) the inchoative verb złamać sie 'break ${ }_{\text {incho }}$ ' is derived from the alternating verb stem $z$ łamaćstem 'break stem $_{\text {st }}$ ' with the help of się. Likewise, in the Hungarian example in (16b) the suffix -ad is a reflex of the derivation of megszárad 'dry ${ }_{\text {incho }}$ ' from the alternating verb stem (meg)szár- 'dry stem $_{\text {' }}$.

In summary, the essence of the present analysis of the causative-inchoative alternation is that a causative-inchoative verb and its inchoative counterpart are both derived from their shared alternating verb stem. This is modelled in $L$ by means of the functions $\kappa$ and $v$ that each apply to a causative-inchoative alternating pair (relative to a choice of $P, R$, and $R^{\prime}$ ) to yield a causative-inchoative derivative and an inchoative derivative, respectively. I now turn to the main consequences of this analysis.

\subsection{Consequences}

In the semantics presented in the previous section, causative-inchoative verbs denote types of events that possibly have an agent and inchoative verbs denote types of events that are not necessarily caused by an agent. This means that the derivation of a causative-inchoative verb will fail if no agent is possible and the derivation of an inchoative verb will fail if a causing agent is necessary. This in turn offers a way of accounting for the missing verbs in (4)-(6) and (7)-(9). Let's consider each of these cases in turn.

The first case actually has two subcases, depending on whether the change of state has an agent or the causing event lacks an agent. Beginning with the former, we can show that if the first member of a causative-inchoative alternating pair entails that the theme is also an agent, then the extension of the causative-inchoative derivative is necessarily empty. More precisely, we have:

$$
\begin{aligned}
& \text { Fact. } \quad \forall \mathrm{R} \forall \mathrm{P} \forall \mathrm{R}^{\prime}\left[\forall \mathrm { e } \forall \mathrm { y } \left[\left(\text { Caus-Incho-Alt-Pair }\left(\mathrm{R}(\mathrm{P}), \mathrm{R}^{\prime}\right)\right)_{0}(\mathrm{e}, \mathrm{y}) \rightarrow\right.\right. \\
& \text { Agent(e,y)] } \rightarrow \\
& \left.\square \neg \exists \mathrm{e}^{\prime} \exists \mathrm{x} \exists \mathrm{y}^{\prime}\left[\kappa\left(\text { Caus-Incho-Alt-Pair }\left(\mathrm{R}(\mathrm{P}), \mathrm{R}^{\prime}\right)\right)\left(\mathrm{e}^{\prime}, \mathrm{x}, \mathrm{y}^{\prime}\right)\right]\right]
\end{aligned}
$$

Observe that the antecedent of the main conditional in (29) is satisfied if the changes of state are not pure changes of state. Basically, the problem is that if the kind of 
change of state in question is not a pure change of state, then it is not possible for it to be agent-caused by an agent.

For an application of this result, consider the analysis of the alternating

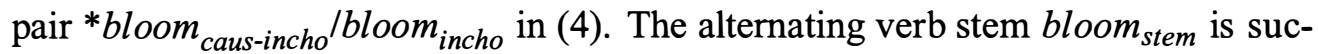
cinctly represented as in (30), analogous to the analysis of break $k_{\text {stem }}$ in (24), though with the difference that the theme of the change of state is also an agent. This asserts that changes of state in which something blooms are not pure changes of state. Assuming this analysis, the fact in (29) is applicable and the extension of the causative-inchoative derivative of BLOOM is empty, as stated in (31). Strictly speaking, although there is no morphological prohibition against deriving the causative-inchoative verb *boom $_{\text {caus-incho }}$, if we were to derive it, it would have an empty denotation.

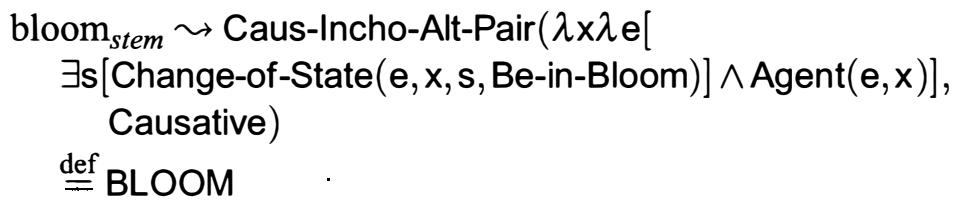

(31) Fact. $\square \neg \exists \mathrm{e} \exists \mathrm{x} \exists \mathrm{y}[\kappa(\operatorname{BLOOM})(\mathrm{e}, \mathrm{x}, \mathrm{y})]$

But how plausible is it that the theme argument of bloom $_{\text {incho }}$ is also an agent? If the roses in Rebecca's garden bloom, are they really agents of their own blooming? Of course, roses do not bloom intentionally or consciously, but there is a sense in which they 'do something' when they bloom. Notice that whereas the question/answer pair in (32a) is completely normal, the one in (32b) is anomalous. ${ }^{15}$

a. What did the roses do? They bloomed.

b. \#What happened to the roses? They bloomed.

With respect to this do-test, bloom $_{\text {incho }}$ contrasts with break $_{\text {incho }}$, which denotes pure changes of state (see (28)):

(33) a. \#What did the pencil do? It broke.

b. What happened to the pencil? It broke.

Thus, it seems plausible that if the roses bloom, then they are both the themes and the agents of the blooming, much as Rebecca is both the theme and the agent of the jumping if she jumps into the water. And this has the consequence that there is no

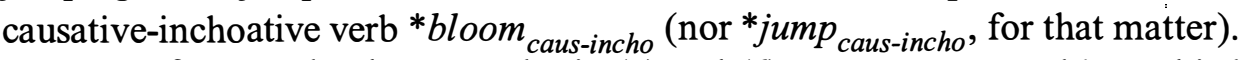
of treatment:

Unfortunately, the examples in (5) and (6) are not so amenable to this kind

(34) a. \#What did the iron gate do? It rusted away.

b. What happened to the iron gate? It rusted away.

a. ?What did the fire do? It burned out.

b. What happened to the fire? It burned out. 
The results of the do-test are not very encouraging, as far as the potential agenthood of the iron gate and the fire is concerned. However, another possibility is that the verb stems rust away stem $_{\text {and }}$ anrn out ${ }_{\text {stem }}$ simply impose the restriction that the performer argument is not an agent. This leads to the second subcase alluded to above. In effect, this amounts to a selectional restriction on the range of external arguments for the would-be causative-inchoative verbs * rust away caus-incho and *burn out $_{\text {caus-incho }}$. But note that the consequence of imposing this restriction is that such potential causative-inchoative verbs necessarily have an empty extension, as stated in (36).

$$
\begin{gathered}
\text { Fact. } \quad \forall R \forall P \forall R^{\prime}\left[\forall e \forall x \left[\exists e^{\prime}\left[\left(\text { Caus-Incho-Alt-Pair }\left(\mathrm{R}(\mathrm{P}), \mathrm{R}^{\prime}\right)\right)_{1}\left(\mathrm{e}, \mathrm{x}, \mathrm{e}^{\prime}\right)\right] \rightarrow\right.\right. \\
\neg \text { Agent }(\mathrm{e}, \mathrm{x})] \rightarrow \\
\left.\square \neg \exists \mathrm{e}^{\prime \prime} \exists \mathrm{x}^{\prime} \exists \mathrm{y}\left[\kappa\left(\text { Caus-Incho-Alt-Pair }\left(\mathrm{R}(\mathrm{P}), \mathrm{R}^{\prime}\right)\right)\left(\mathrm{e}^{\prime \prime}, \mathrm{x}^{\prime}, \mathrm{y}\right)\right]\right]
\end{gathered}
$$

In brief, the problem is that a causative-inchoative verb should be possibly agentive, and yet this possibility is excluded if the alternating verb stem imposes the selectional restriction that the causer argument is not an agent.

As an illustration, I present the analysis of burn out stem $_{\text {(in the sense of The }}$ fire burned out) as a causative-inchoative alternating pair in (37) and I state the result (as an application of the fact in (36)) that its causative-inchoative derivative necessarily has an empty denotation in (38).

$$
\begin{gathered}
\text { burn out }_{\text {stem }} \leadsto \text { Caus-Incho-Alt-Pair }(\lambda \times \lambda \mathrm{e}[ \\
\exists \mathrm{s}[\text { Pure-Change-of-State }(\mathrm{e}, \mathrm{x}, \mathrm{s}, \text { Be-Burned-Out })]], \\
\left.\lambda \mathrm{e}^{\prime} \lambda \times \lambda \mathrm{e}\left[\text { Causative }\left(\mathrm{e}, \mathrm{x}, \mathrm{e}^{\prime}\right) \wedge \neg \text { Agent }(\mathrm{e}, \mathrm{x})\right]\right) \\
\stackrel{\text { def }}{=} \text { BURN-OUT }
\end{gathered}
$$

\section{Fact. $\square \neg \exists \mathrm{e} \exists \mathrm{x} \exists \mathrm{y}[\kappa(\mathrm{BURN}-\mathrm{OUT})(\mathrm{e}, \mathrm{x}, \mathrm{y})]$}

The second case mentioned at the outset is that the derivation of an inchoative verb will fail if the performer argument is an agent. More precisely, if the second member of a causative-inchoative alternating pair implies that the performer is an agent, then the denotation of the inchoative derivative is necessarily empty:

$$
\begin{gathered}
\text { Fact. } \quad \forall R \forall P \forall R^{\prime}\left[\forall e \forall x \left[\exists \mathrm{e}^{\prime}\left[\left(\text { Caus-Incho-Alt-Pair }\left(\mathrm{R}(\mathrm{P}), \mathrm{R}^{\prime}\right)\right)_{1}\left(\mathrm{e}, \mathrm{x}, \mathrm{e}^{\prime}\right)\right] \rightarrow\right.\right. \\
\begin{aligned}
\text { Agent }(\mathrm{e}, \mathrm{x})] \rightarrow \\
\left.\square \neg \exists \mathrm{e}^{\prime \prime} \exists \mathrm{y}\left[\boldsymbol{v}\left(\text { Caus-Incho-Alt-Pair }\left(\mathrm{R}(\mathrm{P}), \mathrm{R}^{\prime}\right)\right)\left(\mathrm{e}^{\prime \prime}, \mathrm{y}\right)\right]\right]
\end{aligned}
\end{gathered}
$$

Consider the examples in (7)-(9) in the light of this fact. It is plausible that the kinds of events denoted by these causative-inchoative verbs in these sentences necessarily involve an agent, for only agents (and not instruments or natural forces) can break promises, crack codes, or dirty diapers (in the relevant sense of dirty caus-incho $_{\text {) }}$. There is perhaps a sense in which computers can crack secret codes, but this is true only by virtue of running certain software that was written by agents-computers qua hardware cannot do such things. For instance, if the verb stem dirty stem is analyzed as in (40), then it follows (as an application of the fact in (39)) that the denotation of the would-be inchoative verb ${ }^{*}$ dirty $_{\text {incho }}$ is necessarily empty, as stated 
$\mathrm{V}_{\text {incho }}-\mathrm{V}_{\text {caus-incho }}$

Figure 7: The traditional model

in (41).

$$
\begin{aligned}
& \text { dirty }_{\text {stem }} \leadsto \text { Caus-Incho-Alt-Pair }(\lambda \times \lambda \mathrm{e}[ \\
& \exists \mathrm{s}[\text { Pure-Change-of-State }(\mathrm{e}, \mathrm{x}, \mathrm{s}, \mathrm{Be}-\text { Dirty })]] \\
& \left.\quad \lambda \mathrm{e}^{\prime} \lambda \times \lambda \mathrm{e}\left[\text { Causative }\left(\mathrm{e}, \mathrm{x}, \mathrm{e}^{\prime}\right) \wedge \text { Agent }(\mathrm{e}, \mathrm{x})\right]\right) \\
& \stackrel{\text { def }}{=} \mathrm{DIRTY}
\end{aligned}
$$

(41) Fact. $\square \neg \exists \mathrm{e} \exists \mathrm{x}[\mathrm{v}(\mathrm{DIRTY})(\mathrm{e}, \mathrm{x})]$

In order to be able to predict the unacceptability of $* b_{r e a k_{i n c h o}}$ in $(7 \mathrm{~b})$, we have to distinguish two meanings for the verb stem break $_{\text {stem }}$. The one meaning is the sense of concrete breaking illustrated in (1) and analyzed in (24): concrete breakings do not require an agent. The other meaning is the sense of abstract breaking exemplified in (7a): abstract breakings do require an agent. Such a distinction is not an artefact of the present approach but has to be drawn in any account that does not want to conflate these two notions of breaking.

\section{Comparisons}

Many authors have written about the causative-inchoative alternation, and so a word or two about how the present analysis fares against the competition is in order. Broadly speaking, there are three main approaches to the causative-inchoative alternation, due to tradition, Parsons (1990), and Levin and Rappaport Hovav (1995), respectively. ${ }^{16}$

According to what I call the traditional model, causative-inchoative verbs are derived from their inchoative counterparts via a causativization operation, as depicted in Figure 7. Dowty (1979, sect. 4.3) adopts a version of the traditional model and would assign essentially the following representations to break incho $_{\text {and }}$ break $_{\text {caus-incho }}$, respectively:
a. break $_{\text {incho }} \sim \lambda x[$ Become Broken $(x)]$
b. break $_{\text {caus-incho }} \sim \lambda y \lambda x[\exists P[P(x)$ Cause Become Broken $(y)]]$

The traditional model suffers from two main problems. The first is that it does not do justice to the morphological facts of the causative-inchoative alternation crosslinguistically. Perhaps this is not surprising, given that it was originally designed for English, which generally favors labile alternations (to use Haspelmath's term) that reveal next to nothing about the order of derivation, but it is a liability nonetheless. In particular, anticausative alternations and equipollent alternations are utterly mysterious if causative-inchoative verbs are derived from inchoative verbs. The second problem is that the traditional model has no natural way of deriving causative-inchoative verbs from nonexistent inchoative verbs (see (7)-(9)). More- 


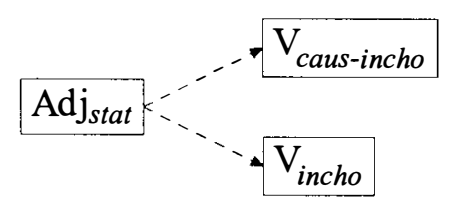

Figure 8: Parsons's (1990) model

over, it is unclear what prevents the causative-inchoative verbs in (4)-(6) from being derived.

Parsons (1990, chap. 6) arguably proposes a model in which both causativeinchoative verbs and inchoative verbs are derived from related stative adjectives, as depicted in Figure 8. ${ }^{17}$ Ignoring irrelevant details, Parsons would assign the following analyses to break $k_{\text {incho }}$ and break ${ }_{\text {caus-incho }}$, respectively:

$$
\begin{aligned}
& \text { a. } x \text { break }_{\text {incho }} \leadsto \exists e[\text { Theme }(e, x) \wedge \exists s[\operatorname{Be}-\operatorname{Broken}(s) \wedge \operatorname{Theme}(s, x) \wedge \\
& \operatorname{Become}(e, s)]] \\
& \text { b. } x \text { break }_{\text {caus-incho }} y \sim \exists e\left[\operatorname { A g e n t } ( e , x ) \wedge \exists e ^ { \prime } \left[\operatorname{Cause}\left(e, e^{\prime}\right) \wedge \operatorname{Theme}\left(e^{\prime}, y\right) \wedge\right.\right. \\
& \exists s[\operatorname{Be}-\operatorname{Broken}(s) \wedge \operatorname{Theme}(s, x) \wedge \operatorname{Become}(e, s)]]
\end{aligned}
$$

In a certain respect, Parsons's model is congenial to the one that I propose (see Figure 1) in that it also does not attempt to linearly derive causative-inchoative verbs from inchoative verbs or vice versa. At the same time, though, the claim that the derivational source is always an adjective seems incredible in view of the crosslinguistic morphological facts. For instance, this approach entails that one function of the reflexive clitic sie in Polish (see (10)-(12)) would be to derive inchoative verbs from stative adjectives. But this means that sie would have to both be morphologically category-changing (adjective to verb) and semantically contribute the change-of-state predicate Become - an altogether improbable scenario for a reflexive clitic, not to mention that in examples such as złamać sie 'break ${ }_{\text {incho }}$ ' there is no adjective in sight.

The other problem is that Parsons's approach offers no explanation of why causative-inchoative verbs sometimes lack an inchoative counterpart (see (7)-(9)) and of why inchoative verbs sometimes lack a causative-inchoative counterpart (see (4)-(6)). Yet in the absence of a story about such examples, Parsons's analysis contains an awkward redundancy in that the change-of-state predicate Become has to be contributed by both the derivation of causative-inchoative verbs from stative adjectives and the derivation of inchoative verbs from stative adjectives, as can be inferred from the representations in (43). It is difficult to see what is gained by this redundancy.

Levin and Rappaport Hovav (1995, chap. 3) present a model in which inchoative verbs are derived from causative-inchoative verbs, as depicted in Figure 9. They emphasize that this process of derivation consists solely in the detransitivization of causative-inchoative verbs - inchoative verbs and causative-inchoative verbs otherwise have the same semantic representation, as shown for $b r e a k_{\text {incho }}$ and break $_{\text {caus-incho }}$ in (44). 


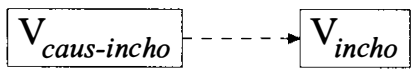

Figure 9: Levin and Rappaport Hovav's (1995) model

$$
\begin{aligned}
& x \text { break }_{\text {caus-incho }} y, \quad y \text { break }_{\text {incho }}: \\
& \quad[[x \text { Do-something] Cause [y Become Broken }]]
\end{aligned}
$$

While Levin and Rappaport Hovav's approach does justice to anticausative alternations crosslinguistically, it encounters difficulties with causative alternations and equipollent alternations. What should we say about Khalka Mongolian (see (13)) or Hungarian (see (14)-(16)) if inchoative verbs are always derived from causative-inchoative verbs? Another difficulty lies in Levin and Rappaport Hovav's claim that causative-inchoative verbs and inchoative verbs share the same semantic representation: this entails that inchoative verbs are semantically dyadic and causative, on a par with their causative-inchoative counterparts, but unfortunately there is virtually no evidence indicating that this is case. ${ }^{18}$

To end on a more positive note, Levin and Rappaport Hovav deserve credit for addressing the question of why causative-inchoative verbs sometimes lack an inchoative counterpart (see (7)-(9)), ${ }^{19}$ for which they suggest (p. 107) the following condition on the detransitivization of a causative-inchoative verb: "an externally caused verb can leave its cause argument unexpressed only if the nature of the causing event is left completely unspecified." This sounds different from what I propose, namely, that inchoative verbs denote types of changes of state that are not necessarily caused by an agent, but it may come down to the same thing, given that to specify an agent is certainly to specify something about the nature of the causing event. But their condition still sounds more general than mine, because for them any specification about the nature of the causing event should block the derivation of an inchoative verb. Whether this is true or not depends on what it means to specify something about the nature of the causing event and on what we might want to specify about different types of causing events anyway. In any case, the status of their condition is unclear, given that it is not explicitly built into their analysis.

\section{Endnotes}

* An earlier version of this paper was presented at SALT 11 at New York University on 13 May 2001. I am grateful to that audience for their useful questions and comments, and I thank the editors of this volume for their patience. This paper is also available at http://www.phil-fak.uni-duesseldorf.de/ pinon/papers/flcia.html. This work was supported by the German Science Foundation (SFB 282, Teilprojekt D3).

${ }^{1}$ Since I restrict my attention to the causative-inchoative alternation and do not discuss the causative alternation more generally, I do not ask, as Levin and Rappaport Hovav (1995, (41), p. 101) do, why burn in The fire burned does not show the 
causative alternation (cf. * The campers burned the fire). I do not ask this question because burn on this reading is not an inchoative verb. Nevertheless, I do ask the related question of why the inchoative verb burn out lacks a causative-inchoative counterpart-see (6).

${ }^{2}$ The verbs in (4)-(6) are examples of what Levin (1993, sect. 45.5) classifies as 'verbs of entity-specific change of state'. As Levin observes (see also Levin and Rappaport Hovav (1995, pp. 87, 99)), such verbs are sometimes sporadically used transitively with a causer argument but even then the range of permissible causers is very restricted.

${ }^{3}$ Inchoative verbs that are otherwise problematic can sometimes appear unproblematically in the middle construction. For example, The secret code cracked easily is much more acceptable than (8b) (but notice that?Her promise broke easily (cf. (7b)) is still rather dubious). However this is to be accounted for, it is essential to exclude the interpretation characteristic of the middle construction when judging such examples.

${ }^{4}$ The examples in (13) are taken from Haspelmath (pp. 117-118). It is not evident to me whether the affixes $-e$ and $-l g$ are two allomorphs of the same morpheme or not rather two different morphemes ( $-e$ is presumably a vowel harmonic alternant of $-a$ ).

${ }^{5}$ Haspelmath (p. 115) classifies felébreszt/felébred 'wake up ${ }_{\text {caus-incho }} /$ wake up $_{\text {incho }}$ ' (see (14)) and other alternating pairs in Hungarian with these endings as causative alternations, but this is a mistake, because they are actually equipollent alternations. ${ }^{6}$ And it should also be emphasized that few if any languages are completely consistent with respect to the main pattern that they adopt.

${ }^{7}$ Since $-\dot{c}$ is the infinitival suffix in Polish, the verb stem may not include it.

${ }^{8}$ This corresponds to a system of modal logic known as $S 5$.

${ }^{9}$ Thus an event can have two performers as long as the one is an agent and the other, an instrument. Note, incidentally, that this notion of performer differs from the one employed by Parsons (1990, p. 78), according to which performers may be instruments or natural forces but not agents.

${ }^{10}$ See Sommerhoff (1969) for an elucidation of the notion of goal-directedness intended here.

${ }^{11}$ Another condition might be that if $e$ causes $e^{\prime}$, then $e$ is not a part of $e^{\prime}$.

${ }^{12}$ A possibility that I do not consider here is that the state variable $s$ in Figure 2 is not (yet) bound by an existential quantifier. Piñon (1999) entertains this possibility in a rather different context - that of durative adverbials for result states.

${ }^{13}$ More precisely, if $w=\langle a, b\rangle$, then $(w)_{0}=a$ and $(w)_{1}=b$.

${ }^{14} \operatorname{In}(26)$ and elsewhere I will omit the universally quantified conditions originating from Figure 4 if they are clearly satisfied.

${ }^{15}$ Cruse (1973) discusses this test (known as the do-test) in detail. A possibility not excluded by this test is that the roses are natural forces, akin to the wind or the rain. However, this is where the idea of goal-directedness, mentioned in section 2.1 and studied by Sommerhoff (1969), comes in: blooming is goal-directed behavior for a rose in a way that blowing down a tree is not goal-directed behavior for the wind. ${ }^{16}$ I discuss these three approaches more fully in Piñón (2001). 
${ }^{17}$ Since Parsons is not explicit about derivations, it is hard to be certain, but see his remark on p. 120 in this regard. However, if I am mistaken and he really intends to implement the traditional model, then so much the worse.

${ }^{18}$ Härtl (2000) examines the issue of whether inchoative verbs are dyadic and causative and concludes that they are not. See also Piñón (2001, sect. 2.2).

${ }^{19}$ Though trying to account for why inchoative verbs sometimes lack a causativeinchoative counterpart (see (4)-(6)) is trickier if inchoative verbs are derived from causative-inchoative verbs, as in Levin and Rappaport Hovav's approach.

\section{References}

Brousseau, Anne-Marie and Ritter, Elizabeth. 1991. A non-unified analysis of agentive verbs. In Dawn Bates (ed.), Proceedings of the Tenth West Coast Conference on Formal Linguistics, 53-64. Stanford: CSLI Publications.

Cruse, D. A. 1973. Some thoughts on agentivity. Journal of Linguistics 9, 11-23.

Dowty, David R. 1979. Word meaning and Montague Grammar: The semantics of verbs and times in Generative Semantics and in Montague's PTQ. Dordrecht: D. Reidel.

Härtl, Holden. 2000. Conceptual and grammatical characteristics of argument alternations: The case of decausative verbs. Ms., University of Leipzig.

Haspelmath, Martin. 1993. More on the typology of inchoative/causative verb alternations. In Bernard Comrie and Maria Polinsky (eds.), Causatives and transitivity, 87-120. Amsterdam: John Benjamins.

Levin, Beth. 1993. English verb classes and alternations: A preliminary investigation. Chicago: The University of Chicago Press.

Levin, Beth and Rappaport Hovav, Malka. 1995. Unaccusativity: At the syntaxlexical semantics interface. Cambridge, MA: The MIT Press.

Parsons, Terence. 1990. Events in the semantics of English: A study in subatomic semantics. Cambridge, MA: The MIT Press.

Piñón, Christopher. 1999. Durative adverbials for result states. In Sonya Bird, Andrew Carnie, Jason D. Haugen, and Peter Norquest (eds.), Proceedings of the 18th West Coast Conference on Formal Linguistics, 420-433. Somerville, MA: Cascadilla Press. (Also available at http://www.phil-fak. uni-duesseldorf.de/ pinon/papers/dars.html.)

Piñón, Christopher. 2001. Modelling the causative-inchoative alternation. Linguistische Arbeitsberichte 76, 273-293. University of Leipzig. (Also available at http://uww.phil-fak.uni-duesseldorf.de/ pinon/papers/mcia.html.)

Sommerhoff, Gerd. 1969. The abstract characteristics of living systems. In F. E. Emery (ed.), Systems thinking, 147-202. Harmondsworth, England: Penguin Books.

van Voorst, Jan. 1995. The semantic structure of causative constructions. Studies in Language 19, 489-523. 